\title{
ARTICLE
}

Received 30 Jul 2013 | Accepted 28 Nov 2013 | Published 8 Jan $2014 \quad$ DOl: 10.1038/ncomms4035

\section{Natural wetland emissions of methylated trace elements}

\author{
Bas Vriens ${ }^{1,2}$, Markus Lenz ${ }^{3,4}$, Laurent Charlet $^{5}$, Michael Berg ${ }^{1} \&$ Lenny H.E. Winkel ${ }^{1,2}$
}

Natural wetlands are well known for their significant methane emissions. However, trace element emissions via biomethylation and subsequent volatilization from pristine wetlands are virtually unstudied, even though wetlands constitute large reservoirs for trace elements. Here we show that the average volatile fluxes of selenium $\left(<0.12 \mu \mathrm{g} \mathrm{m}^{-2}\right.$ day $\left.^{-1}\right)$, sulphur $\left(<37 \mu \mathrm{g} \mathrm{m}^{-2} \mathrm{day}^{-1}\right)$ and arsenic $\left(<0.54 \mu \mathrm{g} \mathrm{m}^{-2}\right.$ day $\left.^{-1}\right)$ from a pristine peatland are considerable and consistent over two summers. We compare these fluxes with the total concentrations in the peat and show that selenium is up to 40 times more efficiently volatilized than arsenic, and over 100 times more efficiently volatilized than sulphur. We further show that the volatilization of selenium and arsenic increases with temperature, implying that emissions of these health-relevant trace elements will increase with global warming. We suggest that biomethylation and volatilization in wetlands play a crucial role in the mobilization and global biogeochemical cycling of trace elements.

\footnotetext{
${ }^{1}$ Eawag, Swiss Federal Institute of Aquatic Science and Technology, Dubendorf CH-8600, Switzerland. ${ }^{2}$ Institute of Biogeochemistry and Pollutant Dynamics, ETH Zurich, Zurich CH-8092, Switzerland. ${ }^{3}$ University of Applied Sciences and Arts Northwestern Switzerland, School of Life Sciences, Institute for Ecopreneurship, Muttenz CH-4132, Switzerland. ${ }^{4}$ Department of Environmental Technology, Wageningen University, Wageningen 6708 WG, The Netherlands. ${ }^{5}$ Earth Science Institute (ISTerre), University of Grenoble-I, Grenoble F-38041, France and Institut Universitaire de France, Paris 75005, France. Correspondence and requests for materials should be addressed to L.H.E.W. (email: lenny.winkel@eawag.ch).
} 
$\mathrm{T}$ he trace element selenium (Se) is essential for human health ${ }^{1}$. However, many agricultural soils are deficient in bioavailable Se, and it is estimated that up to 0.5 to 1 billion people have deficient Se intake ${ }^{2}$. Despite the importance of Se for human health, crucial aspects of the biogeochemical behaviour of Se in the environment are poorly understood. An important contribution to global Se cycling is suggested to be biological methylation and subsequent volatilization to the atmosphere ${ }^{3,4}$. However, global scale estimates of this Se flux are based on little experimental evidence and contain large uncertainties ${ }^{4}$.

In the terrestrial environment, quantification of Se volatilization has almost exclusively been done in contaminated environments in the frame of (phyto-)remediation of Se-rich soils, such as in the San Joaquin Valley in California (US) ${ }^{5}$. Atmospheric Se fluxes have been characterized in Se-enriched areas using socalled closed-box methods (also dynamic flux chambers) ${ }^{6,7}$ and in laboratory incubation experiments of soils ${ }^{8,9}$, which have often been amended with carbon and/or Se to promote volatilization ${ }^{7}$. Globally, however, Se-contaminated sites are relatively small in size and number compared with the larger and more prevalent Se-deficient regions. Field and laboratory studies investigating atmospheric Se fluxes from Se-deficient environments are scarce. Volatilization may decrease available Se in soils, thus worsening Se deficiency, and subsequent atmospheric deposition may increase Se concentrations in surface environments. Quantification of volatile Se fluxes that control terrestrial Se distribution in natural (pristine) environments is therefore essential.

Wetlands constitute $\sim 6-11 \%$ of the world's land area and are significant reservoirs in the biogeochemical cycle of carbon and other major and trace elements ${ }^{1}$. Biomethylation is an important biogeochemical process in carbon-rich environments such as wetlands. Biomethylation of sulphur (S) occurs in marine and terrestrial environments, and contributes significantly to the global biogeochemical S cycle (mostly via dimethyl sulphide $(D M S))^{11}$. Due to chemical similarities between Se and S, it has been postulated that the elements have similar biomethylation pathways $^{12,13}$. Similarly to Se, arsenic (As) is a trace element irregularly distributed in soils and groundwater, and elevated levels of inorganic As in groundwater in Southeast Asia, for example, have resulted in serious human health problems ${ }^{14}$. Similar to Se and S, As also forms organic, methylated species in nature $^{15,16}$. Methylation and subsequent volatilization of As have been quantified in laboratory experiments (for example, incubation studies with contaminated soils ${ }^{17}$ ) but rarely in natural environments ${ }^{18,19}$.

Since the (bio)geochemistry of Se and As is closely interlinked with $\mathrm{S}$ in many environments ${ }^{13,20}$, investigating the biogeochemical cycles of Se and As in relation to that of $\mathrm{S}$ is important. In this context, we study volatilization and surface concentrations of Se, S and As simultaneously from a minerotrophic peatland in Southern Switzerland (Fig. 1), using a novel gas-trapping technique where nitric acid is applied as a trapping liquid and using state-of-the-art speciation methods. We report simultaneous volatile Se, S and As fluxes and speciation from a pristine wetland, and show that Se has a considerably higher relative volatilization efficiency than $S$ and As.

\section{Results}

Elemental emissions from the peatland. Figure $2 \mathrm{a}, \mathrm{b}$ depicts the amounts of volatile Se, $\mathrm{S}$ and As trapped from the air over the peat bog over the course of 10 days and 14 days in 2010 and 2012, respectively. The cumulative trapped Se, S and As concentrations in the 2012 campaign are best described by a linear fit $\left(R^{2}>0.77\right.$ for all elements), indicating similar and relatively constant emissions during the experiment. From the slope of the linear fit to the cumulative total trapped elemental concentrations, we calculated the average volatilization fluxes over the total duration of the field campaign: $0.11 \mu \mathrm{g} \mathrm{Se} \mathrm{m}^{-2}$ day $^{-1}$,

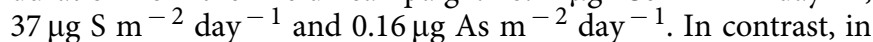
2010, the fluxes decreased towards the end of the campaign, and the overall trends were better described by parabolic functions $\left(R^{2}>0.96\right.$ for Se and As). In the 2010 campaign, the fluxes were $0.12 \mu \mathrm{g} \mathrm{Se} \mathrm{m}{ }^{-2}$ day $^{-1}$ and $0.54 \mu \mathrm{g} \mathrm{As} \mathrm{m}^{-2}$ day $^{-1}$ in the first $75 \mathrm{~h}$ (linear period) of the experiment.

The calculated Se flux in 2010 is similar to that in 2012, whereas the calculated As flux of 2010 was 3.5 times higher than in 2012. Differences in the absolute amount and trends of volatilization of Se and As in 2010 and 2012 are potentially explained by spatial ${ }^{21}$ and temporal heterogeneity in peat element concentration (for example, due to precipitation and surface water flow) during the two field campaigns (Supplementary Fig. 1). No systematic relation between the Se and As concentrations in the trapping liquids is observed, but a positive correlation between the S and Se concentrations in the trapping liquids is observed with a linear correlation coefficient $R^{2}=0.60 \quad(N=13)$ over a wide concentration range (see Supplementary Fig. 2).

A thorough comparison of the observed fluxes of Se, S and As in this study with those observed in earlier studies is provided in Supplementary Table 1. Summarized, the recorded flux of volatile $\mathrm{S}\left(37 \mu \mathrm{g} \mathrm{m}^{-2}\right.$ day $\left.^{-1}\right)$ is within the same order of magnitude as previous field and laboratory experiments with soils but lower than the fluxes measured from sediments. The recorded fluxes of total As $\left(0.16-0.54 \mu \mathrm{g} \mathrm{m}^{-2} \mathrm{day}^{-1}\right)$ are higher than the total As fluxes observed earlier in field and laboratory studies of pristine and amended soils, possibly due to local enrichments of As at the surface of the peat in Gola di Lago $^{20,21}$. In contrast, the recorded fluxes of volatilized Se $\left(0.11-0.12 \mu \mathrm{g} \mathrm{m}^{-2}\right.$ day $\left.{ }^{-1}\right)$ are considerably lower than the total Se fluxes measured from Se-rich soils (both in the field and in laboratory studies). These differences in fluxes imply that volatilization estimates of Se, S and As may vary significantly depending on the studied environmental system and experimental conditions, and more importantly, that natural endogenous Se volatilization may be consistently overestimated from studies conducted on Seenriched peat or soils ${ }^{22}$, either in field studies or using laboratory incubations. In order to accurately assess global emissions of trace elements from pristine environments, it is thus crucial to determine volatilization fluxes of trace elements from representative natural environments.

The relationship between volatilization rates of Se, $\mathrm{S}$ and $\mathrm{As}$ and prevailing surface water temperatures is given in Fig. 3 and the relationship between air temperature and volatilization rates is given in Supplementary Fig. 3. An increased rate of volatilization with increasing temperatures of both surface water and air can be observed, for example, for surface water, a 15 to $40 \%$ increase of volatilization of the studied elements was observed over a $5{ }^{\circ} \mathrm{C}$ rise in temperature. The best fits for the temperature-volatilization relationships were obtained by non-linear regression (polynomial): Se $(N=13): R^{2}>0.66, \mathrm{~S}(N=15): R^{2}>0.79$ and As $(N=11)$ : $R^{2}>0.70$. The present study is the first to report the temperature dependence of Se volatilization rates in a pristine (unamended) field site. A comparison with previous studies (see Supplementary Discussion) reveals that Se volatilization in the studied pristine environment is up to five times less temperature dependent than observed in earlier studies ${ }^{23}$. In addition, a comparison of the slopes and shapes of the fitted curves in Fig. 3 and Supplementary Fig. 3 suggests that Se volatilization is less dependent on temperature than the volatilization of $S$ and As, which could indicate that different kinetics and volatilization mechanisms govern the emissions of Se, As and S. 
a

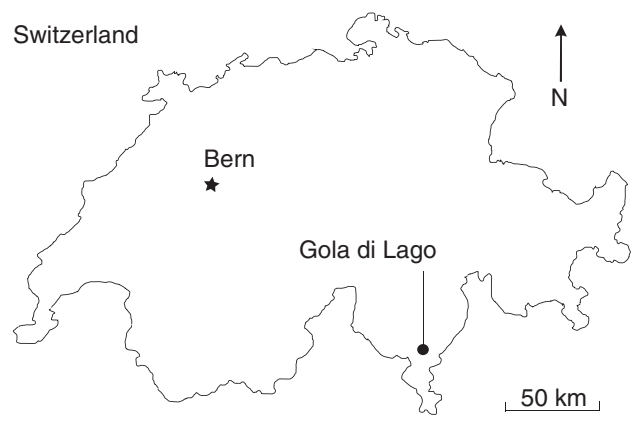

b

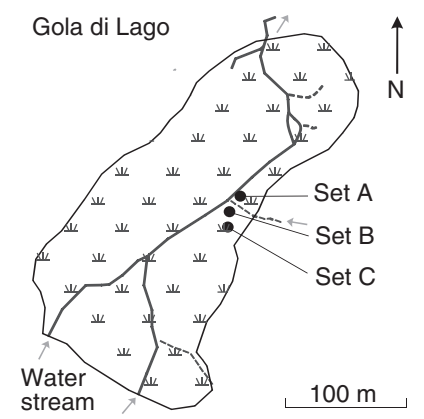

C

Trapping set
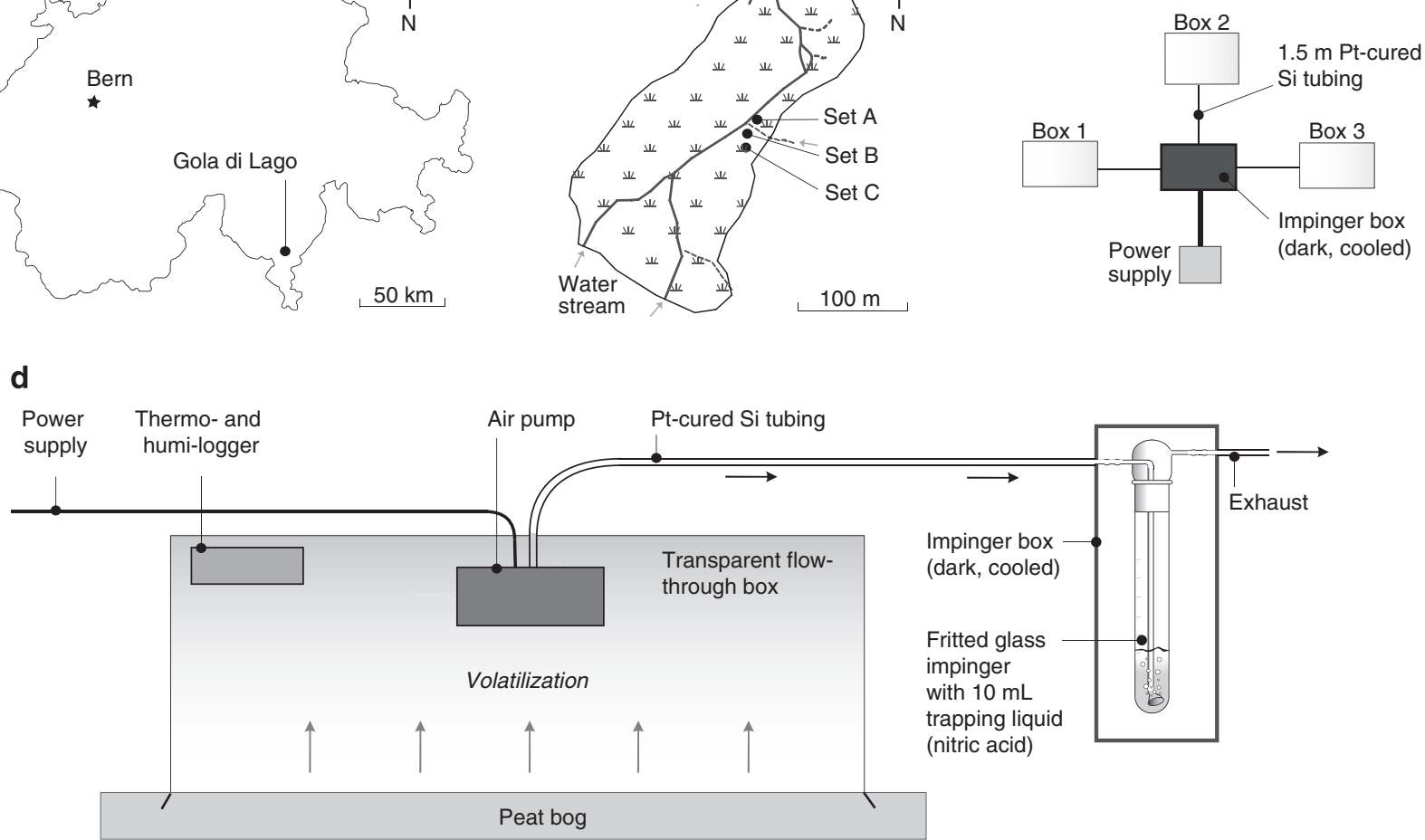

Figure 1 | Field location and experimental schematic. (a) Geographical location of Gola di Lago, Southern Switzerland. (b) Schematic map of the peat bog area 20 , with locations of trapping sets A, B and C. (c) Diagram depicting the experimental setup with triplicate flow-through boxes. (d) Illustration of a single flow-through box connected to a glass impinger filled with the trapping liquid (nitric acid). The flow-through boxes were placed in the peat bog, in an area partially inundated and partially overgrown by vegetation (for details on vegetation ${ }^{20}$ ). Each box was placed over a roughly similar proportion of inundated surface and vegetation.

Speciation of volatilized selenium and sulphur. Speciation of volatilized Se and $\mathrm{S}$ was investigated in trapping liquids containing $>1 \mu \mathrm{gl}^{-1}$ Se or $>50 \mu \mathrm{gl} 1^{-1} \mathrm{~S}$ (Fig. 2c,d). The samples varied in both the total concentrations and the abundance of the trapped species. The fraction of organic, methylated species in the trapping liquids was dominated by monomethylated species (see Fig. 2c,d): MSeA (trapping product of DMDSe) was present in all samples, and MSA (trapping product of DMDS) was observed in all but one sample. Di-methylated Se (DMSeO; trapping product of DMSe) was detected in one, and di-methylated S (DMSO; trapping product of DMS) in three out of six samples (abbreviations and details in Table 1 and Supplementary Methods). The speciation of volatilized As was not investigated because of demethylation and the consequent loss of information of speciation during trapping (B. Vriens et al., unpublished data).

DMDSe has been previously detected in air and water ${ }^{24,25}$ and in incubated soils ${ }^{26}$, and DMDS has been measured in air and soils in natural and laboratory systems ${ }^{27}$. However, previous studies suggested that DMDSe in terrestrial environments is strongly retained on soil particles and thus not efficiently volatilized $^{28}$. It is currently believed that DMSe and DMS volatilization is more significant than DMDSe and DMDS volatilization $^{8,11,29}$. In addition to trapping products of DMDSe and DMDS, the dominating presence of MSeA and MSA in the trapping liquids could also be explained by other processes, such as atmospheric oxidation of DMSe inside the flow-through box before trapping in the acid traps (which potentially leads to the formation of MSeA in analogy to atmospheric gas-phase reactions of $\mathrm{S}^{30}$ ) or the trapping of other species that are naturally produced (for example, dimethyl selenenyl sulphide
$\left(\mathrm{CH}_{3} \text {-Se-S-CH}, \mathrm{DMSeS}\right)^{31}$, methane selenol $\left(\mathrm{CH}_{3}-\mathrm{Se}-\mathrm{H}\right)^{24}$ and methane thiol $\left(\mathrm{CH}_{3}-\mathrm{S}-\mathrm{H}\right)^{27,32}$. Furthermore, the anionic species selenate $\left(\mathrm{SeO}_{4}\right)$ and sulphate $\left(\mathrm{SO}_{4}\right)$ were present in the trapping liquids, which may be the result of oxidation of inorganic gas species (hydrogen sulphide $\left(\mathrm{H}_{2} \mathrm{~S}\right)$, carbonyl sulphide (COS), carbon disulphide $\left(\mathrm{CS}_{2}\right)^{11}$ and Se analogues). Finally, variable amounts of unidentified species (calculated from the total elemental concentration minus the sum of all identified species) were present in the trapping liquids (Fig. 2c,d). Our results indicate that the speciation of volatile Se may be more complex than primarily volatilization of DMSe, which has often been assumed to be the main form of volatile $\mathrm{Se}^{7}$, in analogy to DMS. Because the gaseous speciation may affect atmospheric transformations and thus atmospheric lifetime and mobility, additional insight into the speciation and physicochemical behaviour of volatilized Se, S and As is required.

Peat composition and surface water speciation. The concentrations of Se, S and As in the surface peat sampled in the 2012 campaign were $2.0 \pm 0.4 \mathrm{mg} \mathrm{kg}^{-1} \mathrm{Se}, 4500 \pm 700 \mathrm{mg} \mathrm{kg}^{-1} \mathrm{~S}$ and $75 \pm 35 \mathrm{mg} \mathrm{kg}^{-1}$ As, on a dry weight basis. The detected concentrations are similar to previously reported concentrations of these elements in the surface peat ${ }^{20,21}$. Although As was previously shown to coincide with enrichment of $S$ in Gola di Lago $^{21}$ (and explained by complexation with sulphide groups in organic matter in the form of thio-arsenate ${ }^{20}$ ), in this study, $S$ and As concentrations in the peat were not correlated.

The total concentrations of Se, S and As in the surface water of the 2012 campaign varied considerably, and the low Se 

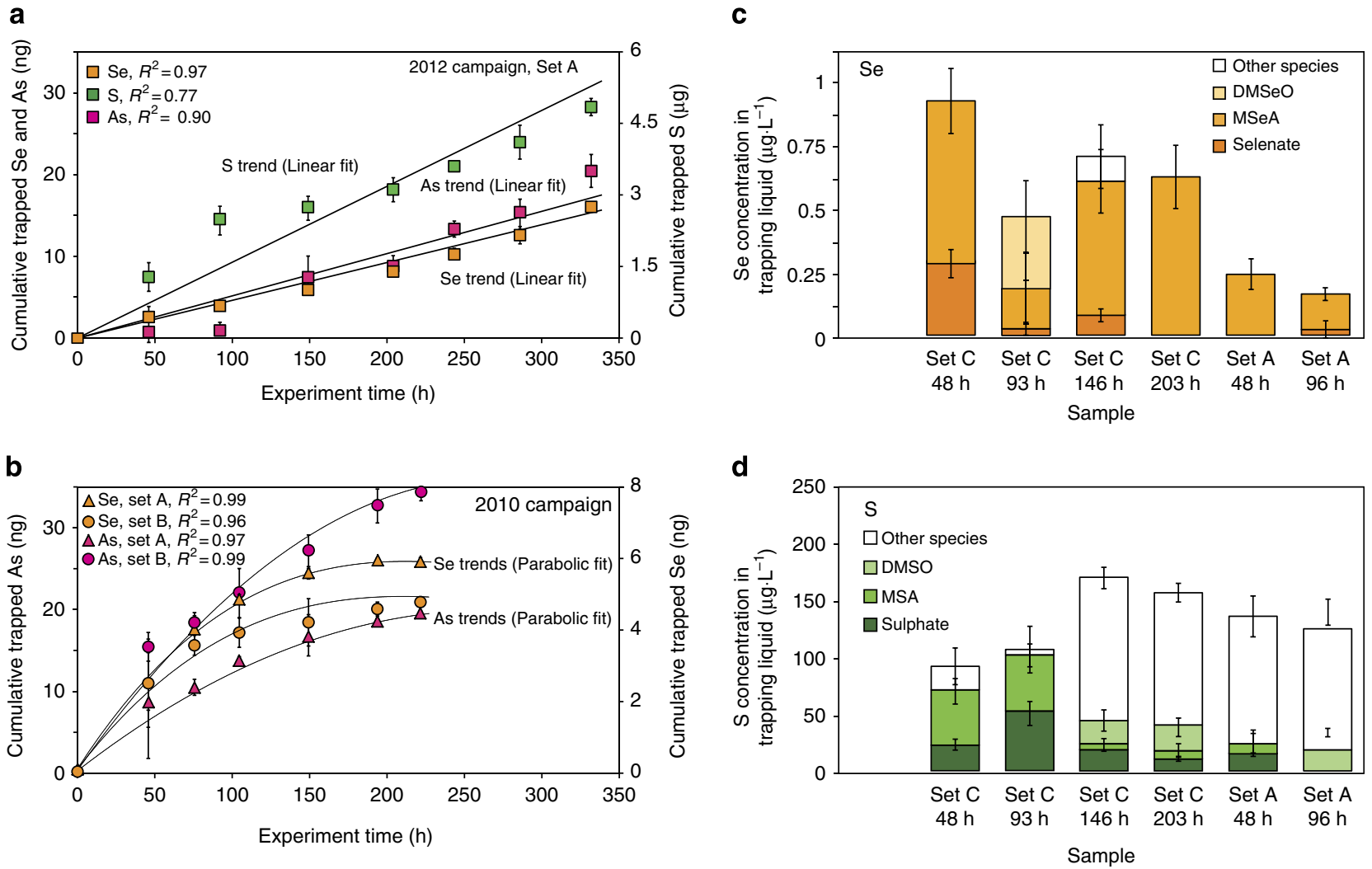

Figure 2 | Emissions from the peatland and gaseous speciation. (a) Cumulative total amounts of trapped Se, S and As (error bars indicate the s.d. of the triplicate boxes) in set $A$ in 2012, with linear trend lines and correlation coefficients $\left(R^{2}\right)$ thereof. (b) Cumulative total amounts of trapped Se and As (error bars indicate the s.d. of triplicate boxes) in sets $A$ and B in 2010, with polynomial trend lines and correlation coefficients $\left(R^{2}\right)$ thereof. (c) Speciation of Se and (d), S in selected traps, with indicated sampling times (from sets A and C, 2012 campaign). The fraction of unidentified species (other species) was determined by the difference between the total elemental determination and the sum of all identified species. Error bars indicate the s.d. of the measurements of triplicate samples.

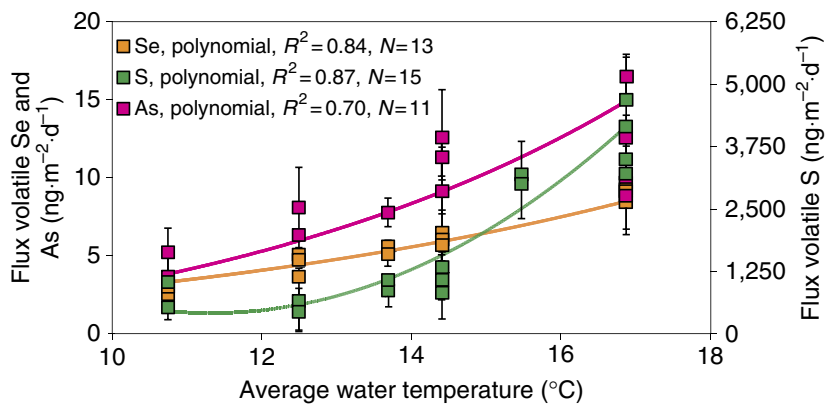

Figure 3 | Temperature dependence of emissions. Relationship between the observed volatile fluxes of $\mathrm{Se}, \mathrm{S}$ and $\mathrm{As}$ and the $24 \mathrm{~h}$ average temperature of surface water (sets A and C, 2012 campaign). The volatile fluxes were calculated from the measured concentrations in the acid traps and correlated with the recorded temperatures within the corresponding trapping period. The trend lines illustrate the best fit non-linear regressions, with regression type, correlation coefficient $\left(R^{2}\right)$ and number of measurements $(N)$ indicated per element. The error bars represent the s.d. of the measurements of triplicate trapping liquid samples.

concentrations (on average $0.08 \mu \mathrm{gl}^{-1}$ ) indicate that Se was relatively depleted in the aqueous phase (Fig. 4a). After rainfall, the elemental concentrations of most elements decreased due to dilution (as indicated by decreasing concentrations of conservative elements such as magnesium and calcium). Redox potential

\section{Table 1 | Original volatile Se and S species and corresponding non-volatile trapping products.}

\begin{tabular}{l} 
Original volatile species \\
\hline DMSe
\end{tabular}

and $\mathrm{pH}$ values ranged between -51 and $+118 \mathrm{mV}$ (versus SHE) and 4.8 and 6.75 , respectively (see also Supplementary Fig. 4), which can be considered characteristic for suboxic and slightly 
a

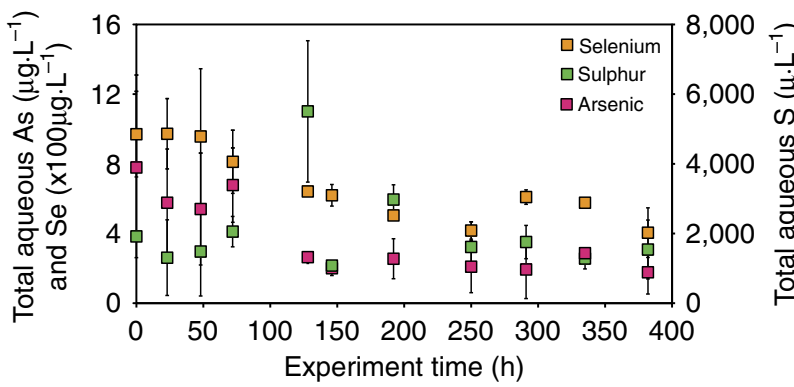

b

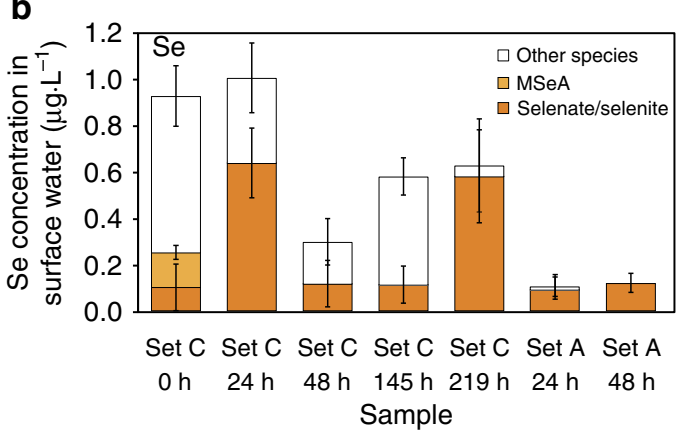

C

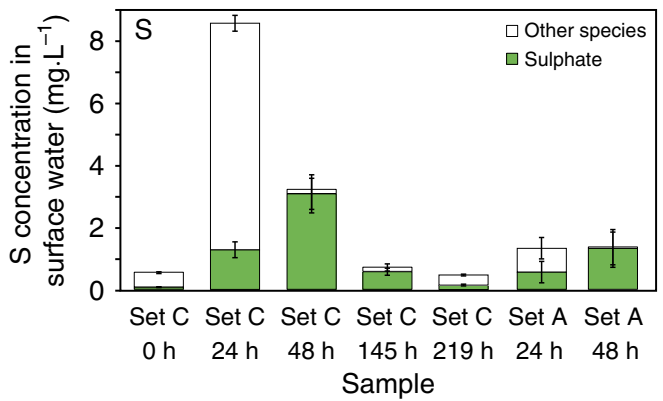

d

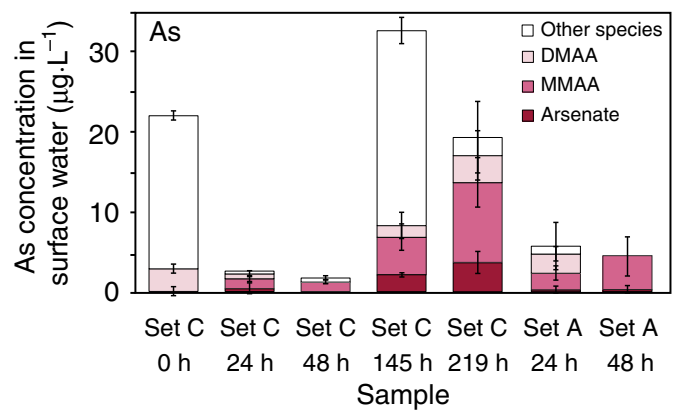

Figure 4 | Surface water composition and speciation. (a) Total concentrations of Se, S and As in surface water of set A in 2012. (b) Speciation of non-volatile Se, (c) S and (d) As of selected surface water samples (sets A and C, 2012 campaign), sampled at the indicated sampling times. Errors bars indicate the s.d. of the measurements of triplicate samples.

acidic peatland waters. No significant correlations were observed between aqueous elemental concentrations or speciation and surface water parameters such as dissolved oxygen content, redox potential, $\mathrm{pH}$ and conductivity.

Figure $4 \mathrm{~b}-\mathrm{d}$ depicts the Se, $\mathrm{S}$ and As species quantified in surface water samples (samples were collected parallel to trapping liquid samples shown in Fig. 2c,d). Non-volatile, methylated Se (in the form of MSeA) was present in only one of the seven analysed surface water samples, and to our knowledge, MSeA has not previously been reported in natural aqueous samples. Other surface water samples contained selenite $\left(\mathrm{SeO}_{3}\right)$ and selenate $\left(\mathrm{SeO}_{4}\right)$ only. Sulphate was detected in all analysed surface water samples, but no dissolved methylated forms of S (DMSO or MSA) were identified. In contrast, the surface water was richer in nonvolatile methylated As than inorganic As (methylated As was present in the form of monomethyl arsenic acid and dimethyl arsenic acid; trimethyl arsenoxide was not observed), which agrees with other studies ${ }^{16}$ that identified monomethyl arsenic acid and dimethyl arsenic acid as important organoarsenic compounds in natural waters. All surface water samples contained a fraction of unidentified species. Since no unmatched peaks occurred within $90 \mathrm{~min}$ in anion chromatography, other anionic species of Se, S or As were excluded as present in significant concentrations. The fraction of unidentified species is most likely explained by dissolved gaseous species or by (overall) neutral or cationic species (for example, complexes with organic matter, colloidal $\mathrm{Se}^{33}, \mathrm{~S}$ or $\mathrm{As}^{34}$, or elemental Se, which is thermodynamically the most stable species in water at slightly acidic and redox neutral conditions ${ }^{33}$ ). Although combined As-S or Se-S species have been observed in natural waters (for example, thio-arsenates in geothermal waters $^{35}$, or DMSeS in marine waters ${ }^{31}$ ), the absence of corresponding peaks for Se, S or As indicates that such species were not significantly present in the surface water samples.

Substantial methylation and volatilization from the peat bog could be inferred from the large fractions of methylated Se and S species in trapping liquids (Fig. 2c,d). However, potential methylated precursors for volatile species were scarcer than inorganic Se and S species in the aqueous phase (Fig. $4 \mathrm{~b}-\mathrm{d}$ ). This dissimilarity between the speciation of the trapping liquids and surface waters may be caused by a rapid exchange of volatile species from the aqueous phase with the atmosphere (volatile, methylated species of Se and S were only indirectly measured in the gaseous phase), or by plant-mediated volatilization. Many plants are known to directly secrete volatile (methylated) $\mathrm{Se}^{13}$, which does not necessarily involve transport through the surface water.

Preferential volatilization of selenium. To assess the relative efficiency of volatilization for Se, S and As, the measured concentrations in the trapping liquids were compared with those in the peat and surface water. The absolute volatilization efficiency $\left(\eta_{\mathrm{vol}}\right)$ of an element $\mathrm{X}$ is defined as follows:

Volatilization efficiency from surface water to air:

$$
\eta_{\text {vol }}=\frac{[X]_{\mathrm{air}}}{[X]_{\text {water }}} \times \frac{V_{\text {air }}}{V_{\text {water }}}
$$

Volatilization efficiency from peat to air:

$$
\eta_{\text {vol }}=\frac{[X]_{\text {air }}}{[X]_{\text {peat }}} \times \frac{V_{\text {air }}}{V_{\text {peat }}}
$$

where $[X]_{\text {air }}$ is the average concentration of element $X$ in air (over the entire field campaign), $[X]_{\text {water }}$ and $[X]_{\text {peat }}$ are the average concentrations of element $X$ in the surface water and surface peat (over the entire field campaign), respectively. $V_{\text {air }}, V_{\text {water }}$ and $V_{\text {peat }}$ are the volumes of air, surface water and surface peat considered in the calculation (details in Supplementary Table 2). A schematic comparison of the relative volatilization efficiencies of Se, S and As, obtained by normalizing the absolute volatilization efficiencies to that of Se, is shown in Fig. 5. Selenium was on average 110 times more efficiently volatilized from the aqueous phase 


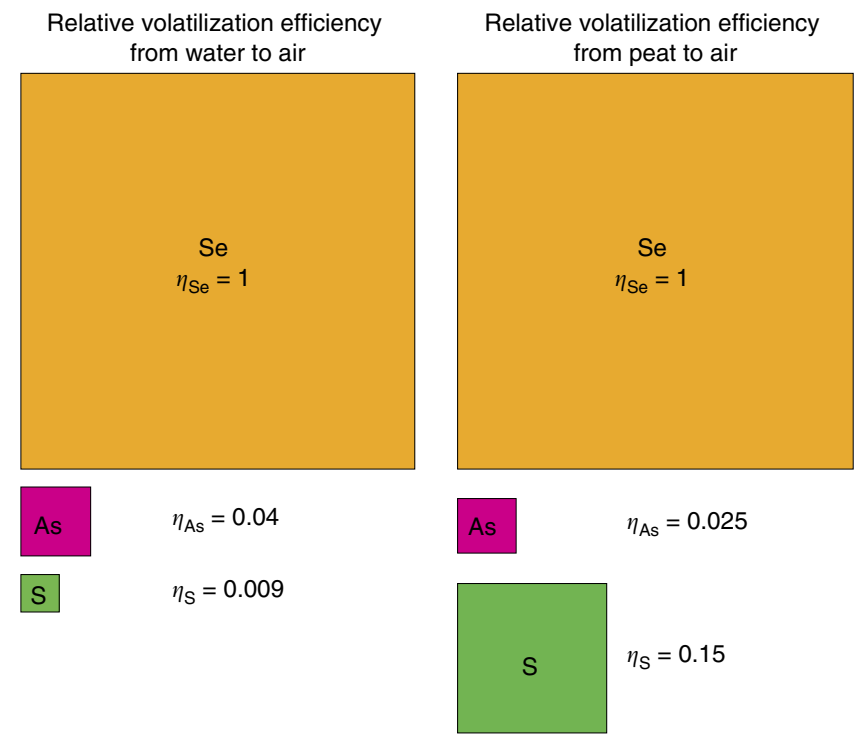

Figure 5 | Preferential volatilization of selenium. Diagram illustrating the relative volatilization efficiency $\left(\eta_{\mathrm{vol}}\right)$ of Se over As and $\mathrm{S}$ by the size of the squares. The relative volatilization efficiency is calculated for water to air (left) and peat to air (right), using average measured concentrations in air, water and peat from set A of the 2012 field campaign. Details provided in Supplementary Table 2.

than S and 27 times more efficiently than As. Considering the volatilization efficiency calculated with concentrations in the surface peat, Se was on average seven times more efficiently volatilized than $\mathrm{S}$, and on average 40 times more efficiently volatilized than As.

To explain the volatilization rates and efficiencies from the peatland, we consider production processes ((bio)formation of methylated volatile species) and loss factors (for example, demethylation reactions and outgassing of the volatile species to the atmosphere through the air-peat or air-water interface). To start with production processes, methylation and volatilization of Se and S in the environment are known to be mainly the result of biocatalysis, involving different pathways in multistep enzymatic reactions ${ }^{13,27}$. The fact that trapped Se and $S$ concentrations are positively correlated (Supplementary Fig. 2), although $S$ is volatilized to a much higher extent than Se on an absolute scale (on average up to a factor 335), might indicate that $\mathrm{Se}$ is volatilized by the same enzymatic system(s) as $S$ due the chemical similarities between these elements ${ }^{13,33}$. For instance, thioether S-methyltransferase (EC 2.1.1.96) catalyses the methyl group transfer on DMSe and DMS with similar affinities $\left(K_{\mathrm{m}} 1\right.$ and $0.4 \mu \mathrm{M}$, respectively) ${ }^{36}$. However, whereas the aqueous $\mathrm{S}$ concentrations in this study were still considerable (up to $84 \mu \mathrm{M}$, Fig. $4 \mathrm{a}$ ), the low aqueous Se oxyanion concentrations (max $\sim 1 \mathrm{nM}$, Fig. 4a) can hardly induce specific Se volatilizing enzymes for detoxification, which is often presumed to be the main driver for methylation of $\mathrm{Se}^{37}$. Furthermore, the higher volatilization efficiency of Se over As may be caused by the fewer required intermediates in the methylation process of Se compared with $\mathrm{As}^{13,15}$, which concurrently may explain the abundance of non-volatile, methylated As in the surface water.

In addition, the relatively more efficient volatilization of Se over $S$ and As might be explained by the reduction step in the multistep methylation pathway ${ }^{13,15}$. By comparing the energy gain that a reduction reaction of major aqueous species of $\mathrm{Se}, \mathrm{S}$ and As can yield (Gibbs free energies of reduction reactions leading to possible hydride intermediates in the reduction pathway are given in Supplementary Table 3), it becomes evident that reduction of $\mathrm{Se}$ (from $\mathrm{SeO}_{3}$ or $\mathrm{SeO}_{4}$ ) provides two to three times more energy than the reduction of $\mathrm{S}$ (from $\mathrm{SO}_{4}$ ) and $\mathrm{As}$ (from arsenate $\left(\mathrm{AsO}_{4}\right)$ ). This suggests that the reduction of $\mathrm{Se}$ is favourable over the reduction of $\mathrm{S}$ and As, and Se accumulation may take place in organisms (such as observed in plants $^{38,39}$ and marine algae ${ }^{31,40}$ ). Subsequent (un-)selective volatilization could explain the higher volatilization efficiency. An estimated lower apparent activation energy for Se emissions compared to $S$ and As emissions (Supplementary Discussion and Supplementary Fig. 5) agrees with the relatively higher Se volatilization efficiency compared with $S$ and As volatilization efficiencies. In a study in marine waters during a phytoplankton bloom $^{31}$, not only a similar positive correlation between volatile methylated Se and S such as observed in the present study was found (Supplementary Fig. 2), but also relatively more volatile Se than $S$ was measured, compared with what could be expected from the concentrations of dissolved inorganic forms of Se and $S$ in seawater. Because an entirely different enzymatic pathway may underlie methylation in the marine environment, our results indicate that Se may be efficiently volatilized in different environments, irrespective of the exact mechanism of biomethylation.

In addition to variations in the methylation process, observed differences in volatilization may be due to specific transformation processes for certain species, before the trapping process. Demethylation reactions by strict anaerobes (for example, Methanococcus) are improbable, on the one hand due to the (sub-)oxic conditions ( -51 to $+118 \mathrm{mV}$ ) at the wetland surface, and on the other hand because of the low aqueous $\mathrm{Se}$ concentrations $(\mathrm{nM})^{41,42}$. More plausible are abiotic oxidation and demethylation reactions (for example, atmospheric instability and photo-oxidation in the transparent flow-through box), but comparing the reactions for Se, S and As is impeded by a lack of mechanistic and kinetic information, and further investigation is required.

Finally, differences in the exchange of volatile species with the atmosphere could be responsible for the differences observed in the volatilization efficiencies. Potential outgassing of dissolved volatile species from surface water can be assessed by comparing the vapour pressures and gas-liquid partitioning constants (Henry constants) of individual compounds. Thermodynamic data for species deducted in the trapping experiments are scarce, but vapour pressures and Henry constants of naturally relevant, volatile species of Se, S and As (Supplementary Table 4) indicate that Se species (DMSe or $\mathrm{H}_{2} \mathrm{Se}$ ) are generally less volatile (lower vapour pressure) and more soluble (higher Henry constant) than their structural $\mathrm{S}$ and As analogues (DMS or $\mathrm{H}_{2} \mathrm{~S}$ and TMA or $\mathrm{H}_{3} \mathrm{As}$, respectively). Thus, the physical outgassing of these species probably does not explain the preferential suggesting of Se over S and As, suggesting that biomethylation plays a key role in endogenous volatilization.

\section{Discussion}

Ombrotrophic (rainwater-fed) peat bogs constitute valuable environmental records for atmospheric trace element deposition $^{43}$. However, our study indicates that substantial and variable losses of trace elements may take place in peat bogs due to methylation and subsequent volatilization. Such potential losses via methylation processes need to be carefully considered for all elements that undergo methylation (amongst others $\mathrm{Hg}, \mathrm{Pb}, \mathrm{Sb}$, As and $\mathrm{Se}^{44}$ ), and may present a limitation for the use of peat bogs as archives of atmospheric trace element deposition.

Our field experiments provide the first quantification of fluxes of volatilized Se, As and $S$ measured in a pristine terrestrial 
environment, and our results suggest that wetlands may be significant sources of volatile Se. Extrapolation of observed fluxes $\left(0.11-0.12 \mu \mathrm{g} \mathrm{Se} \mathrm{m}^{-2} \mathrm{day}^{-1}\right)$ to the global wetland area $\left(9 \times 10^{6} \mathrm{~km}^{2}\right)^{45}$ would equal global Se volatilization in the range of $0.19-0.37 \times 10^{9} \mathrm{~g}$ Se per year from wetlands. This flux equals $5-10 \%$ of the currently estimated marine Se volatilization $\left(5-8 \times 10^{9} \mathrm{~g} \text { Se per year }\right)^{29}$ and $1-3 \%$ of estimated global Se emissions $\left(15 \times 10^{9} \mathrm{~g} \text { Se per year }\right)^{29}$. We found that Se and S volatilization are positively correlated (Supplementary Fig. 2), but that Se is up to $40-110$ times more efficiently volatilized than As and $\mathrm{S}$, respectively. Corroborated by results of studies in a mine spoil $^{46}$ and in the North Atlantic Ocean ${ }^{31}$, we suggest that Se is preferentially methylated and volatilized over $\mathrm{S}$ and $\mathrm{As}$ in various environments. Furthermore, the efficient Se volatilization from low Se surface waters suggests that biomethylation of Se is not necessarily only a detoxification mechanism. These new insights accentuate the necessity for a more profound understanding of the underlying mechanisms that govern the biomethylation and volatilization of trace elements.

With increasing temperature, we recorded increasing amounts of Se, As and S in the gas traps, which shows that volatilization of these elements is higher when temperatures are higher, but to a different extent (Supplementary Discussion). This is relevant because the global annual average temperature is projected to rise this century by $1.0-5.5^{\circ} \mathrm{C}$ (ref. 47), and in certain parts of Europe (for example, France, Greece and the Iberian Peninsula) up to $6^{\circ} \mathrm{C}$ during summer ${ }^{48}$. Over a 5 -degree rise in temperature, we observed an $\sim 15 \%$ increase in the production of volatile Se, $\sim 20 \%$ increase in the production of volatile As and an $\sim 40 \%$ increase in the production of volatile $S$ from our study site. This indicates that emissions from wetlands alone may increase with $\sim 0.30-0.54 \times 10^{8}$ g Se per year, $\sim 1-4 \times 10^{8}$ g As per year and $\sim 48 \times 10^{9} \mathrm{~g} \mathrm{~S}$ per year when temperatures increase by $5^{\circ} \mathrm{C}$ (using the fluxes observed in this study). Since global wetlands present large pools of trace elements ${ }^{10}$ and are highly sensitive to climate change ${ }^{49}$, our results indicate that better knowledge of trace element cycling in these environments is indispensable, and that atmospheric fluxes need to be considered in global biogeochemical cycle assessments.

\section{Methods \\ Field campaigns. Experimental field campaigns were conducted in 2010 (3-23 August) and 2012 (20 August-6 September) in the minerotrophic (groundwater and surface water-fed) peatland Gola di Lago (Ticino, Switzerland, $46^{\circ} 06^{\prime} 16.00^{\prime \prime}$ $\mathrm{N} ; 8^{\circ} 57^{\prime} 55.00^{\prime \prime} \mathrm{E}$, area 3 ha, elevation $972 \mathrm{~m}$ a.s.l.) (Fig. 1), which is characterized by geogenic enrichments of As and Se at depth in the peat ${ }^{20,21}$. In the 2010 field campaign, Se and As volatilization fluxes were determined using gas-trapping experiments; in the 2012 field campaign these measurements were \\ complemented by the determination of $S$ volatilization, gaseous speciation analyses, and by qualitative and quantitative analyses of dissolved Se, As and S in the surface water. Furthermore, surface peat samples were collected and analysed for total Se, As and S.}

Gas-trapping experiments. A chemotrapping method was applied in combination with a closed box flow-through system (Fig. 1). Briefly, the chemotrapping method is based on trapping of Se, S and As compounds in concentrated nitric acid, where volatile, methylated Se and S species are converted to non-volatile, specific derivatives. This enables the reconstruction of the original speciation of $\mathrm{Se}$ and S (Table 1), and the determination of the total volatilized quantities of Se, S and As (B. Vriens et al., unpublished data). Flow-through boxes were equipped with temperature $\left({ }^{\circ} \mathrm{C}\right)$ and humidity (\% saturation) data loggers (Humipick, Spirig, Rapperswil, Switzerland) recording at $1 \mathrm{~min}$ intervals. Additional information on the gas sampling experiments is given in the Supplementary Methods.

Surface water sampling and analysis. During the 2012 field campaign, surface water samples were collected at 1 or 2-day intervals by submerging acid-washed $\left(1 \% \mathrm{HNO}_{3}\right) 50 \mathrm{ml}$ polypropylene tubes (Greiner Bio-One GmbH, Frickenhausen Germany) in the upper $5 \mathrm{~cm}$ of the peat bog water. After sampling, the water was immediately filtered using $0.45 \mu \mathrm{m}$ Teflon filters (Faust AG, Schaffhausen, Switzerland). Filtered aliquots $(10 \mathrm{ml}$ each) were kept non-acidified (for surface water speciation analysis) or were acidified using concentrated ultrapure $\mathrm{HNO}_{3}$ (Carl Roth $\mathrm{GmbH}$, Karlsruhe, Germany) to a final concentration of $1 \% \mathrm{HNO}_{3}$ (for total elemental analysis). All water samples were stored in acid-washed $10 \mathrm{ml}$ polypropylene tubes at $10^{\circ} \mathrm{C}$ (for maximum 4 days), and subsequently stored in the dark at $4{ }^{\circ} \mathrm{C}$ until analysis. Before water sampling, the $\mathrm{pH}$, electrical conductivity $\left(\mu \mathrm{Sm}^{-1}\right)$, dissolved oxygen content (\% saturation) and redox potential $(\mathrm{mV})$ were recorded using a field multimeter (Multi 340i, WTW GmbH, Weilheim, Germany). Surface water temperatures were recorded using mercury-free thermometers that were placed in duplicate at $10 \mathrm{~cm}$ depth in the peat bog.

Peat sampling and analysis. Peat samples were collected at $20 \mathrm{~cm}$ below the surface water table at days 1,10 and 18 of the 2012 field campaign, and were stored in the dark in 11 polyethylene zip bags at $10^{\circ} \mathrm{C}$ (for a maximum of 4 days) and subsequently stored at $-20^{\circ} \mathrm{C}$ until processing. One aliquot ( $\sim 10 \mathrm{~g}$ (dry weight)) of the peat material was vacuum-freeze-dried at $-20^{\circ} \mathrm{C}$ for $48 \mathrm{~h}$ (LyoAlpha 10-55, Telstar, Madrid, Spain), and manually ground to fine powder using a ceramic mortar and liquid nitrogen. Digestion of the peat material took place in $15 \mathrm{ml}$ Teflon-tetrafluormetoxil (PTFE-TFM) tubes on an MLS ultraClave 4 (Milestone, Shelton, USA). For digestion, $100 \mathrm{mg}$ of dried and ground peat material was mixed with $4 \mathrm{ml}$ of concentrated ultrapure $\mathrm{HNO}_{3}$, and digested at $230^{\circ} \mathrm{C}$ and 130 bar for $1.5 \mathrm{~h}$. Digests were diluted 1:100 with ultrapure water $(18.2 \mathrm{M} \Omega$, Thermo Fisher, NANOpure, Reinach, Switzerland) to obtain a $1 \% \mathrm{HNO}_{3}$ matrix. For quality control, two samples were digested in triplicate, and three certified reference materials were simultaneously digested (European Community Bureau Reference Standard BCR 62 (Olive Leaves), NCS DC 73349 (Bush Branches and Leaves) and NIST SRM 1515 (Apple Leaves)). The recovery of the certified values was $109-122 \%$ for Se, $108 \%$ for S (only certified in BCR 62) and $76-107 \%$ for As.

Analytical procedures. Total elemental concentrations of Se, S and As in the trapping liquids, peat digests and surface waters and speciation of Se and $S$ in trapping liquids and of Se, $\mathrm{S}$ and As in surface water samples were measured using methods described elsewhere (B. Vriens et al., unpublished data). All chemicals were of analytical grade or higher.

\section{References}

1. Rayman, M. P. The importance of selenium to human health. Lancet 356, 233-241 (2000).

2. Combs, G. F. Selenium in global food systems. Brit. J. Nutr. 85, 517-547 (2001).

3. Reamer, D. C. \& Zoller, W. H. Selenium biomethylation products from soil and sewage sludge. Science 208, 500-502 (1980).

4. Wen, H. \& Carignan, J. Reviews on atmospheric selenium: Emissions, speciation and fate. Atmos. Environ. 41, 7151-7165 (2007).

5. Gao, S., Tanji, K. K., Lin, Z. Q., Terry, N. \& Peters, D. W. Selenium removal and mass balance in a constructed flow-through wetland system. J. Environ. Qual. 32, 1557-1570 (2003).

6. Lin, Z. Q., Cervinka, V., Pickering, I. J., Zayed, A. \& Terry, N. Managing selenium-contaminated agricultural drainage water by the integrated on-farm drainage management system: role of selenium volatilization. Water Res. 36, 3150-3160 (2002).

7. Stork, A., Jury, W. A. \& Frankenberger, W. T. Accelerated volatilization rates of selenium from different soils. Biol. Trace Elem. Res. 69, 217-234 (1999).

8. Thompsoneagle, E. T., Frankenberger, W. T. \& Karlson, U. Volatilization of selenium by Alternaria-Alternata. Appl. Environ. Microb. 55, 1406-1413 (1989).

9. Terry, N., Carlson, C., Raab, T. K. \& Zayed, A. M. Rates of selenium volatilization among crop species. J. Environ. Qual. 21, 341-344 (1992).

10. Charman, D. J. in Encyclopedia of Inland Waters (ed. Likens, G. E.) 541-548 (Academic Press, 2009).

11. Sievert, S. M., Kiene, R. P. \& Schulz-Vogt, H. N. The sulfur cycle. Oceanography 20, 117-123 (2007)

12. Chau, Y. K., Wong, P. T. S., Silverberg, B. A., Luxon, P. L. \& Bengert, G. A. Methylation of selenium in aquatic environments. Science 192, 1130-1131 (1976).

13. Chasteen, T. G. \& Bentley, R. Biomethylation of selenium and tellurium: microorganisms and plants. Chem. Rev. 103, 1-25 (2003).

14. Winkel, L., Berg, M., Amini, M., Hug, S. J. \& Johnson, A. C. Predicting groundwater arsenic contamination in Southeast Asia from surface parameters. Nat. Geosci. 1, 536-542 (2008).

15. Bentley, R. \& Chasteen, T. G. Microbial methylation of metalloids: arsenic, antimony, and bismuth. Microbiol. Mol. Biol. Rev. 66, 250-271 (2002).

16. Anderson, L. C. D. \& Bruland, K. W. Biogeochemistry of arsenic in natural waters: the importance of methylated species. Environ. Sci. Technol. 25, 420-427 (1991).

17. Turpeinen, R., Pantsar-Kallio, M. \& Kairesalo, T. Role of microbes in controlling the speciation of arsenic and production of arsines in contaminated soils. Sci. Total. Environ. 285, 133-145 (2002).

18. Mestrot, A. et al. Field fluxes and speciation of arsines emanating from soils. Environ. Sci. Technol. 45, 1798-1804 (2011). 
19. Planer-Friedrich, B. et al. Speciation of volatile arsenic at geothermal features in Yellowstone National Park. Geochim. Cosmochim. Acta 70, 2480-2491 (2006).

20. Langner, P., Mikutta, C. \& Kretzschmar, R. Arsenic sequestration by organic sulphur in peat. Nat. Geosci. 5, 66-73 (2012).

21. González, Z. I., Krachler, M., Cheburkin, A. K. \& Shotyk, W. Spatial distribution of natural enrichments of arsenic, selenium, and uranium in a minerotrophic peatland, Gola di Lago, Canton Ticino, Switzerland. Environ. Sci. Technol. 40, 6568-6574 (2006).

22. Thompson-Eagle, E. T. \& Frankenberger, W. T. Protein-mediated selenium biomethylation in evaporation pond water. Environ. Toxicol. Chem. 9, 1453-1462 (1990).

23. Frankenberger, Jr W. T. \& Karlson, U. Volatilization of selenium from a dewatered seleniferous sediment: a field study. J. Ind. Microbiol. 14, 226-232 (1995).

24. Amouroux, D. \& Donard, O. F. X. Maritime emission of selenium to the atmosphere in eastern Mediterranean seas. Geophys. Res. Lett. 23, 1777-1780 (1996).

25. Amouroux, D. \& Donard, O. F. X. Evasion of selenium to the atmosphere via biomethylation processes in the Gironde estuary, France. Mar. Chem. 58, 173-188 (1997).

26. Zhang, Y. Q. \& Frankenberger, W. T. Formation of dimethylselenonium compounds in soil. Environ. Sci. Technol. 34, 776-783 (2000).

27. Bentley, R. \& Chasteen, T. G. Environmental VOSCs-formation and degradation of dimethyl sulfide, methanethiol and related materials. Chemosphere 55, 291-317 (2004).

28. Zhang, Y. \& Frankenberger, Jr W. T. Fate of dimethyldiselenide in soil. J. Environ. Qual. 31, 1124-1128 (2002).

29. Mosher, B. W. \& Duce, R. A. A global atmospheric selenium budget. J. Geophys. Res.-Atmos. 92, 13289-13298 (1987).

30. Barnes, I., Becker, K. H. \& Mihalopoulos, N. An FTIR product study of the photooxidation of dimethyl disulfide. J. Atm. Chem. 18, 267-289 (1994).

31. Amouroux, D., Liss, P. S., Tessier, E., Hamren-Larsson, M. \& Donard, O. F. X. Role of oceans as biogenic sources of selenium. Earth Planet. Sci. Lett. 189, 277-283 (2001)

32. Jensen, N. R., Hjorth, J., Lohse, C., Skov, H. \& Restelll, G. Products and mechanisms of the gas phase reactions of NO3 with $\mathrm{CH} 3 \mathrm{SCH} 3, \mathrm{CD} 3 \mathrm{SCD} 3$, CH3SH and CH3SSCH3. J. Atmos. Chem. 14, 95-108 (1992).

33. Fernandez-Martinez, A. \& Charlet, L. Selenium environmental cycling and bioavailability: a structural chemist point of view. Rev. Environ. Sc. Biotech. 8, 81-110 (2009)

34. Fritzsche, A., Rennert, T. \& Totsche, K. U. Arsenic strongly associates with ferrihydrite colloids formed in a soil effluent. Environ. Pollut. 159, 1398-1405 (2011).

35. Planer-Friedrich, B., London, J., McCleskey, R. B., Nordstrom, D. K. \& Wallschläger, D. Thioarsenates in geothermal waters of Yellowstone National Park: determination, preservation, and geochemical importance. Environ. Sci. Technol. 41, 5245-5251 (2007).

36. Mozier, N. M., McConnell, K. P. \& Hoffman, J. L. S-Adenosyl-L-methionine: Thioether S-methyltranferase, a new enzyme in sulfur and selenium metabolism. J. Biol. Chem. 263, 4527-4531 (1988).

37. Truong, H.-Y. T., Chen, Y.-W. \& Belzile, N. Effect of sulfide, selenite and mercuric mercury on the growth and methylation capacity of the sulfate reducing bacterium Desulfovibrio desulfuricans. Sci. Total. Environ. 449, 373-384 (2013)

38. Terry, N., Zayed, A. M., de Souza, M. P. \& Tarun, A. S. Selenium in higher plants. Annu. Rev. Plant Physiol. Plant Molec. Biol. 51, 401-432 (2000).
39. Zhu, Y.-G., Pilon-Smits, E. A. H., Zhao, F.-J., Williams, P. N. \& Meharg, A. A. Selenium in higher plants: understanding mechanisms for biofortification and phytoremediation. Trends Plant Sci. 14, 436-442 (2009).

40. Obata, T., Araie, H. \& Shiraiwa, Y. Bioconcentration mechanism of selenium by a coccolithophorid, Emiliania huxleyi. Plant Cell Physiol. 45, 1434-1441 (2004).

41. Stolz, J. F. \& Oremland, R. S. Bacterial respiration of arsenic and selenium. FEMS Microbiol. Rev. 23, 615-627 (1999).

42. Oremland, R. S. \& Zehr, J. P. Formation of methane and carbondioxide from dimethylselenide in anoxic sediments and by a methanogenic bacterium. Appl. Environ. Microb. 52, 1031-1036 (1986).

43. Roos-Barraclough, F., Givelet, N., Cheburkin, A. K., Shotyk, W. \& Norton, S. A Use of $\mathrm{Br}$ and $\mathrm{Se}$ in peat to reconstruct the natural and anthropogenic fluxes of atmospheric Hg: A 10000-year record from Caribou Bog, Maine. Environ. Sci. Technol. 40, 3188-3194 (2006).

44. Thayer, J. S. Review: biological methylation of less-studied elements. Appl. Organomet. Chem. 16, 677-691 (2002).

45. Lehner, B. \& Döll, P. Development and validation of a global database of lakes reservoirs and wetlands. J. Hydrol. 296, 1-22 (2004).

46. Moreno-Jiménez, E., Clemente, R., Mestrot, A. \& Meharg, A. A. Arsenic and selenium mobilisation from organic matter treated mine spoil with and without inorganic fertilisation. Environ. Pollut. 173, 238-244 (2013).

47. International Panel on Climate Change. Fourth Assessment Report of the Intergovernmental Panel on Climate Change (UN International Panel on Climate Change, Cambridge University Press, 2007).

48. Fischer, E. M. \& Schär, C. Consistent geographical patterns of changes in highimpact European heatwaves. Nat. Geosci. 3, 398-403 (2010).

49. Davidson, E. A. \& Janssens, I. A. Temperature sensitivity of soil carbon decomposition and feedbacks to climate change. Nature 440, 165-173 (2006)

\section{Acknowledgements}

We thank C. Stengel, H. Hagendorfer, N. Homazava, R. Winkel, D. Kistler and I. Brunner for various technical and analytical support. We acknowledge A. Ammann for helpful discussions and assistance with HPLC-HR-ICP-MS measurements. We thank P. Poggiati and M. Sulmoni from the Department of Environment (Ticino, Switzerland) for permission to conduct the field experiments in Gola di Lago. This work was supported by the European Commission (AquaTRAIN MRTN-CT-2006-035420), and the Swiss National Science Foundation (SNF PP00P2_133619 and 200020_138210).

\section{Author contributions}

L.H.E.W. initiated the project while working in the L.C. group. L.H.E.W. attained further funding for the project. B.V., L.H.E.W. and M.L. did the geochemical analyses. B.V., L.H.E.W., L.C., M.L. and M.B. interpreted and discussed the results. B.V. and L.H.E.W. wrote and edited the manuscript with input from all other authors.

\section{Additional information}

Supplementary Information accompanies this paper at http://www.nature.com/ naturecommunications

Competing financial interests: The authors declare no competing financial interests.

Reprints and permission information is available online at http://www.npg.nature.com/ reprintsandpermissions/

How to cite this article: Vriens, B. et al. Natural wetland emissions of methylated trace elements. Nat. Commun. 5:3035 doi: 10.1038/ncomms4035 (2014). 